\title{
Tocqueville, Sarmiento e Alberdi: três visões sobre a democracia nas Américas ${ }^{1}$
}

José Luis Bendicho BEIRED²

\begin{abstract}
RESUMO: Analisaremos comparativamente três importantes ideólogos liberais do século XIX, Tocqueville, Sarmiento e Alberdi, que situados em diferentes continentes discutiram o significado da democracia nos marcos da ordem liberal. Explicaremos os argumentos e conceitos desenvolvidos em algumas de suas obras mais importantes, em articulação às posições políticas e ideológicas por eles sustentados nos contextos específicos em que atuaram.
\end{abstract}

PalaV Ras-chaVe:: Alexis de Tocqueville; Domingo Faustino Sarmiento; Juan Bautista Alberdi.

A construção da nação e de uma ordem política liberal estiveram no centro do debate político e intelectual argentino de meados do século XIX. Ele foi travado num contexto marcado por um multifacetado processo de criação, circulação e apropriação ideológica desenvolvido no âmbito latino-americano, juntamente com a recepção crítica de teorias, obras e propostas originárias dos ambientes europeu e norte-americano. Para tanto foram mobilizados diversos conceitos políticos - soberania, democracia, liberdade, igualdade, razão, indivíduo e povo, dentre outros - reveladores de uma precoce tradição republicana moderna ${ }^{3}$ que, não é demais lembrar, foi plenamente contemporânea à configuração da modernidade política ${ }^{4}$ que na Europa se contrapunha ao tradicionalismo e aos restos do Antigo Regime.

A Democracia na América, de Alexis de Tocqueville, foi uma das publicações que repercutiram em profundidade nos meios intelectuais da América Latina, tornando-se uma referência para o debate sobre os 
caminhos para as transformações da realidade. A análise dos Estados Unidos, levada a efeito por Tocqueville, fascinou notadamente dois intelectuais argentinos portadores de posições liberais e associados à fundação da chamada Argentina moderna: Domingo Faustino Sarmiento e Juan Bautista Alberdi. Entendendo a atividade intelectual como indissociável da ação política, ambos devotaram-se ao trabalho de refletir sobre os problemas nacionais e da América Latina, ao mesmo tempo em que formularam programas políticos alternativos, consubstanciados em duas obras clássicas: Facundo: civilización y barbárie, ${ }^{5}$ de Sarmiento, e Bases y Puntos de Partida para la Organización Política de la Republica Argentina, ${ }^{6}$ de Alberdi. A seguir, estabeleceremos uma análise comparativa entre esses três autores e as respectivas obras, de modo a explicar os seus argumentos e conceitos em articulação às posições políticas e ideológicas por eles tomadas nos seus respectivos contextos históricos. ${ }^{7}$ Temos como preocupação demarcar tanto as afinidades e analogias quanto as diferenças e oposições entre os autores, centrando nossa atenção no significado da democracia, na concepção de cidadania e na relação entre as leis e os costumes. Em relação à Argentina, analisaremos como o debate de tais questões incidiu no modelo de nação vitorioso. Ao final, compararemos a visão dos três autores em relação ao futuro político das Américas.

Consagrado como uma das obras mais importantes da América Latina no século XIX, o Facundo foi elaborado no bojo das lutas políticas que dilaceravam uma parte do continente. Ao escrevê-lo e publicá-lo durante o seu exílio no Chile, ${ }^{8}$ Sarmiento fez muito mais do que um manifesto de acusação contra a política do governador de Buenos Aires, Juan Manuel de Rosas e os demais caudilhos federais argentinos, traçando um profundo e inédito diagnóstico dos males que afligiam a Argentina. ${ }^{9}$ Intuitivamente, Sarmiento percebeu que as suas idéias transcendiam as fronteiras das províncias argentinas, estendendo-se à América Latina, sendo correspondido por uma legião de leitores latino-americanos, que encontraram no Facundo uma fonte de inspiração para explicar os desafios políticos dos seus respectivos países.

Naqueles anos o francês Alexis de Tocqueville era um intelectual 
consagrado internacionalmente pela publicação de A Democracia na América. Publicado em duas partes, uma em 1835 e a outra em 1845, tratava-se de uma inovadora e audaciosa interpretação política sobre uma jovem nação americana, cujo experimento democrático assombrava e fascinava os que acreditavam no aperfeiçoamento da vida política.

Foi justamente em Tocqueville que Sarmiento, então com trinta e quatro anos, buscou espelhar-se e também equiparar-se ao se impor como tarefa desenvolver uma empreitada equivalente para desvendar o enigma da política argentina e latino-americana. Sem modéstia, Sarmiento afirmava no início do Facundo:

À América do Sul em geral, e à República Argentina, sobretudo, fez falta um Tocqueville, que, munido de conhecimentos das teorias sociais (...) revelasse à Europa, à França, (...) este novo modo de ser que não tem antecedentes bem demarcados e conhecidos. ${ }^{10}$

Essa ambição revelou-se profética, pois tão logo Facundo foi publicado no Chile em 1845, a obra obteve ampla repercussão internacional, ${ }^{11}$ celebrizando o nome de Sarmiento como intérprete ilustrado da realidade latino-americana. Nos anos de forte perseguição às forças liberais derrotadas pelos caudilhos federais, os intelectuais assumiram um destacado papel na crítica aos aspectos autoritários impostos pelo novo sistema de poder, cujo principal expoente era o governador Juan Manuel de Rosas, à frente dos demais caudilhos que dirigiam as províncias integrantes da Confederação Argentina. Recordemos que o Estado centralizado fora praticamente uma ficção desde a independência das Províncias Unidas do Rio da Prata, em 1816, em vista dos desentendimentos entre províncias, as quais, em 1820 e novamente em 1827 puseram abaixo o poder central sediado em Buenos Aires. À frente de Buenos Aires entre 1829 e 1852, com um intervalo entre 1832 e 1835, o governo de Rosas representou o conjunto da confederação nas relações exteriores e ao mesmo tempo exerceu o monopólio das rendas do porto de Buenos Aires, assim como o controle sobre a navegação do rio da Prata, o que lhe conferiu um poder excepcional. Extremamente habili- 
doso, conquistou o apoio dos setores populares e da burguesia na Província de Buenos Aires, assim como do seu poder legislativo provincial, que lhe conferiu poderes ilimitados em 1835. Investido de poder absoluto, exerceu uma pressão draconiana sobre os opositores mediante a intimidação, a perseguição e a morte, motivo pelo qual a mazorca ${ }^{12}$ tornou-se um dos maiores símbolos da era rosista.

A fundação da sociedade secreta Associação de Maio foi a saída encontrada por um grupo de intelectuais para organizar os críticos à ordem estabelecida. Entre os seus membros encontravam-se algumas das principais figuras que no futuro seriam consagradas como intelectuais fundadores da nação argentina: Juan Bautista Alberdi, Estebán Echeverria, Juan Maria Gutierrez e Vicente Fidel Lopez. Também chamada "Geração de 37", os ideais desse grupo foram abraçados por Sarmiento, que definiu os seus membros como "os apóstolos da República e da civilização européia", com a expectativa de que os "poderes intelectuais hão de ter parte na direção da República". ${ }^{13}$ Imbuído dos ideais iluministas, na associação os participantes liam e discutiam os autores europeus de correntes diversas - românticos, socialistas utópicos e liberais - , pois neles poderiam ser encontradas as fontes da civilização que faltava às incipientes nações do rio da Prata.

Apesar da preferência pelos autores franceses, os olhos dos intelectuais argentinos voltavam-se sobretudo para os Estados Unidos quando se tratava de buscar exemplos políticos. A opinião de Sarmiento era emblemática da admiração pela experiência política norte-americana:

Agora e desde esses últimos anos, tenho-me voltado para outro sol que não se eclipsa, que nenhuma nuvem oculta: os Estados Unidos. Como teoria, como ação prática, como poder, como influência, como futuro, sob todos os aspectos, a democracia ali encontro-a forte, consistente em si mesma e dominante também como fato. ${ }^{14}$

Entre as características do modelo político norte-americano, consagrado na Constituição de 1787, figuravam o estabelecimento de uma república representativa, federalista e com divisão tripartite do poder. 
Tal experiência revelava-se não só inédita como surpreendente na medida em que contrariava toda a filosofia política escrita até então, a qual considerava impossível a realização de um governo popular num grande território. Isso foi acompanhado de uma tese também inaudita, baseada em uma concepção pessimista da natureza humana, sustentada por James Madison: que as ambições individuais e a falta de virtudes cívicas do povo não constituíam obstáculos para o estabelecimento de um governo democrático estável. Quanto ao risco da tirania de uma facção, resolvia-se também de modo novo, entendendo-se que o choque de múltiplos interesses econômicos e sociais impediria a predominância de um único sobre os demais. ${ }^{15}$ Portanto, o governo democrático posto em prática diferia da forma pura ou direta de democracia, apenas aplicável a pequenos territórios, e configurava um novo conceito de governo democrático, baseado na representação política, equivalente dali em diante a república representativa.

Nos dois volumes de A Democracia na América ${ }^{16}$ é impossível ficarmos imunes à surpresa e admiração de Tocqueville diante da realidade política norte-americana, descrita como completamente diferente da Europa. Enquanto no primeiro volume priorizou a descrição e a explicação do funcionamento da democracia norte-americana sob vários ângulos, no volume seguinte manifesta-se uma abordagem mais teórica, debruçada sobre o aprofundamento da reflexão a respeito da natureza da própria democracia como modelo político. Embora os Estados Unidos continuem sendo a principal referência da análise do segundo volume, Tocqueville busca compreender o papel da democracia na remodelação do processo político, dos comportamentos intelectuais, das crenças e costumes do povo. ${ }^{17}$

Ora, o que mobilizava as preocupações de Tocqueville era a compreensão do fenômeno democrático que se espalhava pela Europa e em especial pela França, geralmente acompanhado pelo espectro da revolução política e social. Ir ao Estados Unidos significou ter uma via de acesso para conhecer um dos caminhos para o futuro político do mundo, uma vez que ali o novo na história parecia revelar-se de modo antecipado à Europa e simultaneamente despido das suas convulsões. 
Na perspectiva de Tocqueville, vemos que a democracia não era um fenômeno fortuito, mas um movimento histórico irresistível de longa duração, por ele denominado "revolução democrática". Consistia num fenômeno de expansão da igualdade entre os homens, contra o qual era inútil lutar, sob o risco do anacronismo histórico e dos seus oponentes serem esmagados pela forças sociais emergentes. Como é sabido, à medida que o absolutismo foi sendo derrotado na Europa, o igualitarismo passou a ser encarado pelas correntes liberais como seu principal oponente, pela ameaça que representava ao direito de propriedade e à participação política restrita às minorias qualificadas. Apesar de pertencer à aristocracia e de não amar a democracia, Tocqueville rendeu-se à força dos fatos e buscou compreender o fenômeno democrático de maneira inovadora mediante uma reflexão que conjugava a igualdade e a liberdade. Segundo ele, a força do igualitarismo era tão penetrante em todos os domínios da vida social norte-americana, que via sérios riscos para a manutenção futura dos direitos individuais, da liberdade de expressão e da pluralidade de pensamento. Os Estados Unidos revelavam ao mundo o perigo do desenvolvimento de um novo tipo de despotismo, dotado de roupagem democrática, uma vez que consentido pelos cidadãos a um Estado crescentemente burocratizado e centralizado. ${ }^{18}$

O enfoque de Tocqueville também ofereceu uma nova abordagem para a explicação dos fenômenos políticos. A democracia e a liberdade deixaram de ser tratados a partir de definições filosóficas ou jurídicas e passaram a ser abordados na prática, na ação concreta dos homens comuns. Uma das principais conclusões presentes na obra era que o fundamento último da democracia americana residia nos costumes moeurs - do povo que tornavam os homens iguais entre $\mathrm{si}^{19}$ : isto é, nas opiniões, comportamentos e crenças que davam forma àquilo que posteriormente foi definido como a cultura política de uma sociedade. A liberdade, por sua vez, foi analisada a partir do controle efetivo dos cidadãos sobre a política e o Estado, sem o que ela desapareceria.

Se a busca de respostas para o enigma político que cercava a vida política norte- americana e argentina foi comum entre Tocqueville e 
Sarmiento, o mesmo não pode ser dito dos diagnósticos e conclusões. Ora, enquanto o francês buscava explicar as condições de funcionamento de uma vigorosa república democrática, Sarmiento buscava desvendar exatamente o contrário, ou seja, os obstáculos que impediam o desenvolvimento de um processo similar no território argentino.

Logo no início de seu livro, Sarmiento surpreende o leitor e o convida a penetrar num mundo tão insondável que apenas o recurso ao espírito de um cadáver poderia ajudar a desvendá-lo: "Espectro terrível de Facundo, vou evocar-te para que, sacudindo o ensangüentado pó que cobre tuas cinzas, te levantes para explicar-nos a vida secreta e as convulsões internas que dilaceram as entranhas de um nobre povo! Tu possuis o segredo, revela-nos!" ${ }^{20}$ O caudilho Facundo Quiroga, também conhecido como "tigre de los llanos", era governador da província de La Rioja, quando foi assassinado numa emboscada ao transitar pela província de Córdoba, em 1835. A autoria do assassinato é incerta, embora tivesse sido acusado o clã político cordobês dos irmãos Reinafé, dos quais dois, o governador José Vicente Reinafé e seu irmão Guillermo, foram julgados, condenados e enforcados em Buenos Aires. Para Sarmiento, a lógica dos fatos levava ao nome de Rosas como verdadeiro mentor da morte de Facundo, no afã de eliminar seus próprios aliados para a obtenção de maiores poderes sobre o conjunto da confederação.

Sarmiento retoma a lenda, segundo a qual Facundo não morrera na emboscada e que um dia retornaria, para argumentar que de fato o espírito bárbaro desse caudilho estava vivo, podendo ser encontrado nas tradições populares, na política e nas revoluções argentinas. Rosas, por sua vez, era definido por Sarmiento como o principal herdeiro de Facundo, a encarnação da sua essência sob uma forma mais acabada, requintada e perfeita, ao transformar em sistema político o que no sanguinário Facundo era apenas instinto desorganizado. Embora o livro de Sarmiento contenha uma biografia de Facundo, como o próprio título original sugere, na verdade o resultado final é muito maior. Os quinze capítulos do livro podem ser divididos em três partes. A primeira dedicada à descrição dos aspectos físicos da Argentina, dos seus tipos populares e as formas de sociabilidade dos pampas, local habita- 
do pelos gaúchos. Tendo tais elementos como pano de fundo, a biografia de Facundo é desenvolvida para mostrar a fatalidade da vida de alguém que crescera naquelas condições socioambientais, por meio de uma narrativa das mais impressionantes sobre a personalidade violenta, fria e sádica de Facundo, cuja vida se encerrara numa tragédia banhada em sangue. Em sua terceira parte, o livro conclui com uma apaixonada acusação do despotismo de Rosas e com a apresentação de um programa de tarefas a serem abraçadas pelo novo governo depois da sua deposição.

Ambos, Sarmiento e Tocqueville foram homens que nas suas obras deixaram impressas as preocupações com a política contemporânea. Que aspectos aproximavam obra e pensamento de dois homens situados em lugares tão distantes no espaço quanto Sarmiento e Tocqueville? Em que pese as grandes diferenças históricas entre a França e a Argentina, ambos os autores compartilhavam de um horizonte ideológico liberal. O mais surpreendente é a similaridade entre o método de ambos para compreender as realidades norte-americana e argentina. $\mathrm{O}$ ponto de convergência reside na abordagem da política a partir da sociedade, na busca de fatores explicativos estruturais inscritos na longa duração.

A novidade do enfoque de ambos encontra-se, portanto, no exercício de uma sociologia "avant la lettre", ao buscarem nas profundezas do social os fundamentos da sociabilidade política. O exemplo disto é que ambos os autores valorizam menos as leis e os grandes homens públicos do que o papel desempenhado pelo homem comum na configuração dos comportamentos políticos das nações. No entanto, a convergência teórica produziu avaliações opostas: enquanto os hábitos dos norte-americanos os tinham conduzido à democracia, aqueles dos argentinos os haviam levado para a barbárie.

Aparentemente as duas abordagens são descritivas ao tratarem os aspectos constitutivos da Argentina e dos Estados Unidos. Assim como Tocqueville dá exemplos dos comportamentos cotidianos dos norte-americanos, Sarmiento descreve a geografia, os gaúchos, as ações de Rosas e traça a biografia de Facundo. No entanto, há nas duas obras 
mais que meras descrições, podendo-se afirmar que encerram de fato tipos ideais manipulados para melhor expressar os pontos de vista de seus autores. Sobretudo no segundo volume de A Democracia na América, Tocqueville debruça-se sobre os Estados Unidos com o objetivo de desenvolver um "modelo de democracia" de caráter mais amplo e universal, no qual predomina o temor do esmagamento da liberdade pela igualdade. ${ }^{21}$

Ainda que esse aspecto já tenha sido assinalado por estudiosos do pensador francês, o mesmo não é tão claro em relação ao livro de Sarmiento. Usando os mesmos filtros ideológicos e culturais do ambiente intelectual da Europa, Sarmiento pôde estabelecer um critério conceitual que lhe permitiu definir a realidade argentina como uma continuação da barbárie dos povos não-europeus. Desse modo, tanto as descrições das paisagens pampeanas quanto dos tipos humanos que ali habitavam, vão sendo construídas em associação com exemplos apropriados de escritores europeus, em cujas obras a Ásia e a África representavam a barbárie, isto é, o outro, em contraponto à civilização européia.

Essa analogia começa pela própria paisagem das planícies do pampa, cuja solidão interrompida por comboios solitários é aparentada com os desertos mesopotâmicos e suas caravanas de camelos. O gaúcho do llano é definido como um beduíno americano, comparável aos árabes por seus hábitos pastoris, tradições patriarcais, vestes, barba e demais aspectos físicos. ${ }^{22}$ Em suma, para Sarmiento a luta que dilacerava a Argentina era um capítulo de um choque maior, de dimensão universal, entre a barbárie e a civilização: "A mesma luta entre civilização e barbárie da cidade e do deserto existe hoje na África; os mesmos personagens, o mesmo espírito, a mesma estratégia indisciplinada entre a horda e a montonera".23

Embora suas descrições dos pampas, dos gaúchos e de Facundo sejam tão convincentes que parece vermos tais paisagens e figuras diante de nós, de fato nosso autor jamais tinha posto os pés na região pampeana e também jamais vira Facundo Quiroga frente a frente, apesar de ter participado das milícias que o combateram. O próprio Sarmiento reconhece no final da introdução do livro a existência de defeitos e 
inexatidões relativas à vida de Facundo. Mas é significativo que afirme não se importar, pois era mais relevante a glória de escritor argentino, destinado a fustigar o mundo e a humilhar a soberba dos grandes da terra, sábios ou governos..$^{24} \mathrm{~A}$ nossa hipótese é que, à maneira de Tocqueville, sob uma brilhante construção literária, Sarmiento também acabou por construir um tipo ideal, um conceito de barbárie que lhe servia para apreciar os traços nefastos da realidade argentina e para justificar seu combate em nome de um projeto liberal de nação.

Ao lado de Sarmiento, Juan Bautista Alberdi foi outro dos principais artífices da ordem política subseqüente à vitória dos liberais sobre Rosas na Batalha de Caseros. Foi responsável pela redação do esboço da Constituição argentina sancionada em 1853, publicado no ano anterior com o título Bases y Puntos de Partida para la Organización Política de la Republica Argentina. A dívida intelectual de Alberdi em relação a Tocqueville era patente, ao reconhecer que por meio dele e de outros franceses ${ }^{25}$ conhecera os Estados Unidos, e definir a Democracia na América como o livro político "mais adequado e mais belo" de quantos tinham chegado às repúblicas sul- americanas. ${ }^{26}$

O diagnóstico da trajetória política e constitucional das republicas latino-americanas foi determinante na definição das questões a serem enfrentadas na nova carta. Nas primeiras décadas depois da independência assistia-se a uma grande frustração das elites liberais quanto aos destinos das jovens repúblicas, muitas delas mergulhadas em guerras civis e convulsões políticas, colocando em xeque a capacidade das constituições conformarem uma nova realidade. ${ }^{27}$ Não por acaso, o livro de Alberdi tem no seu início o exame dos experimentos constitucionais de diversos países latino-americanos, incluindo a Argentina, que tivera duas Constituições promulgadas - em 1819 e 1826 - e anuladas por força dos enfrentamentos políticos contra o governo central. Alberdi se perguntava: Como fazer das nossas democracias nominais, democracias reais? Como transformar em fatos nossas liberdades escritas e nominais? Por meio de que instrumentos elevar a capacidade real dos nossos povos à altura das suas constituições escritas e princípios proclamados? 
Para Alberdi, o papel da Constituição na América Latina era muito mais que o de instrumento legal de organização do poder. Tratavase de um dispositivo para forjar nações tanto em termos das instituições quanto do seu povo. O povo bárbaro deveria dar lugar a outro civilizado com hábitos pautados pelos princípios de liberdade e igualdade, mediante a criação de novas instituições, da mudança da composição étnica, do crescimento econômico, sob a liderança de elites ilustradas. É famosa a assertiva alberdiana segundo a qual, na América Latina, governar significa povoar: "Governar é povoar no sentido de que povoar é educar, civilizar, enriquecer e enriquecer espontânea e rapidamente, como aconteceu com os Estados Unidos". ${ }^{28} \mathrm{Na}$ Argentina, isso traduzia-se do seguinte modo: “(...) a população da Republica Argentina, hoje deserta e solitária, deve ser o grande e primordial fim da sua Constituição por longos anos. Ela deve garantir a execução de todos os meios de obter esse vital resultado. Eu chamarei estes meios garantias públicas de progresso e de engrandecimento" ${ }^{29}$

Dentre as liberdades civis a serem fomentadas destacavam-se o direito de realização de casamentos mistos entre argentinos e estrangeiros, e uma série de liberdades voltadas para o desenvolvimento econômico: adquirir, vender, trabalhar, navegar, comercializar, transitar e exercer todo tipo de industria. A fonte de inspiração da sua proposta era explicitamente a Constituição da Califórnia, de 1849, em função do teor do seu conteúdo, dirigido a promover a economia, o povoamento e a cultura. ${ }^{30}$ Como os demais liberais da época, Alberdi também nutria muita desconfiança quanto à participação política das massas, por ele consideradas grandemente responsáveis pela anarquia política que impedira a consolidação dos governos constitucionais anteriores da Argentina. Para tanto sustentou no seu projeto a implementação de regras que visassem a limitar a participação política dos setores populares de nacionalidade Argentina e a exclusão dos imigrantes da posse de direitos políticos.

Para excluir os imigrantes do processo político, Alberdi dividiu os cidadãos em duas categorias, uma dotada apenas de direitos civis (imigrantes) e outra detentora de cidadania plena, por possuir direitos 
políticos além dos direitos civis (argentinos). De acordo com Natálio Botana, tal divisão do povo significava a coexistência de duas repúblicas simultaneamente, sendo uma formada por "habitantes", voltados para o exercício das funções econômicas, e outra composta por "cidadãos plenos", habilitados para o exercício do poder. ${ }^{31}$ Com a perspectiva futura de uma nação crescentemente habitada por imigrantes europeus, Alberdi reservava o governo do país a uma minoria de cidadãos nascidos na Argentina. Enquanto isso, os imigrantes integrariam um gigantesco exército de trabalhadores industriosos, dotados de direitos civis, porém sem cidadania argentina e, portanto, unicamente orientados à conquista de riquezas materiais, as quais tornariam prósperos tanto seus agentes individuais quanto o conjunto da nação.

Apesar de conceber a cidadania política como potencialmente extensiva a todos os argentinos do sexo masculino, o projeto de Constituição de Alberdi também contemplava mecanismos que visavam a limitar a participação de todos os cidadãos nas diversas etapas das eleições. Tais restrições eram vigentes nos Estados Unidos e foram assinaladas por Tocqueville, variando de acordo com cada Estado da Federação. ${ }^{32}$ Naquela época o assunto também foi debatido pelos liberais europeus, para os quais as restrições eleitorais representariam os "novos mediadores da razão", no papel de filtro que permitiria a seleção da elite dirigente e frearia a interferência das "paixões populares" no processo político. Além desses filtros, outro importante mediador da razão para Alberdi consistiria no predomínio dos "notáveis" no processo eleitoral.

Praticamente toda a proposta de Alberdi para a escolha dos representantes dos Poderes Legislativo e Executivo foi acatada pelos representantes que em 1853 sancionaram a nova Constituição. Segundo o texto aprovado, uma Câmara de Deputados nacionais e um Senado integrariam o Congresso, cujos membros seriam eleitos nas províncias. A eleição para a Câmara de Deputados seria direta e circunscrita aos argentinos do sexo masculino. Os candidatos a senador deveriam ter renda mínima de 2.000 pesos fortes, sendo eleitos indiretamente pelas Assembléias Legislativas provinciais. O presidente da República seria 
eleito mediante um colégio eleitoral com membros a serem designados pelas províncias; cada uma delas deveria indicar um número de membros equivalente ao dobro de deputados e senadores representantes no Congresso. ${ }^{33}$

A formulação alberdiana consistia em uma tradução local da famosa distinção estabelecida em 1819 pelo francês Benjamin Constant entre cidadãos ativos e passivos, ${ }^{34}$ posteriomente reinterpretada por outros liberais, a exemplo de François Guizot. O papel da razão na condução dos assuntos públicos fora sustentado com ênfase por Guizot, que defendia o princípio da "soberania da razão", exercida mediante a participação política do cidadão dotado de certas capacidades, por ele definido como citoyen capacitaire. ${ }^{35}$ A convergência de posições quanto ao exercício da soberania por minorias qualificadas revela que o problema da extensão dos direitos políticos era comum dos dois lados do Atlântico para os ideólogos liberais. Na América Latina, estes não só estavam atualizados com o debate político europeu, mas também produziam respostas específicas aos seus contextos nacionais.

Apesar de compartilharem posições liberais, Sarmiento e Alberdi passaram a se confrontar politicamente logo depois que Rosas foi derrubado. Após a aprovação da nova Constituição em 1853, Sarmiento publicou Comentários de la Constitución de la Confederación Argentina em tom polêmico com as propostas de Alberdi, que por sua vez respondeu na obra Estudios sobre la Constitución Argentina. Alberdi propunha um compromisso entre a tradição e o progresso, materializado na adoção de medidas políticas acordes com o passado colonial (exercício do poder por minorias, centralização política em Buenos Aires) em articulação com outras voltadas para estimular a modernização econômica. Inversamente, Sarmiento propunha a ruptura total com o passado, mediante o transplante da Constituição dos Estados Unidos, ${ }^{36}$ recomendando a naturalização dos imigrantes como argentinos, a difusão da educação gratuita, a descentralização política, o estímulo à vitalidade dos municípios, a distribuição de propriedades rurais e a promoção da agricultura. ${ }^{37}$ Além disso, Sarmiento era crítico da limitação dos direitos políticos aos argentinos natos, assim como das restrições 
para a participação destes no processo eleitoral, situações que no seu entender configuravam um ataque à democracia.

Se em Tocqueville manifesta-se a intervenção de duas forças para garantir a manutenção da democracia americana, as leis e os hábitos - embora estes fossem mais decisivos - também estão presentes nas formulações de Sarmiento e Alberdi. Para este, a barbárie argentina traduzia um fato político - o permanente desrespeito às leis e à autoridade constituída - que só poderia ser corrigido formando-se novos hábitos sociais moldados pela imigração e pelo exercício da atividade econômica. Ou seja, os novos costumes deveriam criar os alicerces para sustentar a longo prazo a vigência das leis consagradas na Constituição. Ao contrário, embora Sarmiento assinalasse no Facundo que nos hábitos do povo residia o principal obstáculo para o desenvolvimento da civilização, no início dos anos 50 alterou a abordagem do problema, passando a defender que a adoção de uma Constituição similar à norte-americana seria um poderoso fator para a mudança da situação "bárbara" da Argentina. Aqui as leis seriam capazes de moldar uma nova realidade social e cultural. Ou seja, enquanto Alberdi via na transformação do tecido social o instrumento para a consolidação da ordem legal e para a expansão futura da cidadania política, Sarmiento via na Constituição o instrumento para alcançar a regeneração da sociedade. Desse modo, no que tange à dialética entre leis e hábitos, Alberdi manteve-se mais próximo que Sarmiento à lógica de Tocqueville ao privilegiar o papel dos costumes como pilar fundamental da República representativa.

A comparação entre Tocqueville, Sarmiento e Alberdi ainda nos apresenta dois outros problemas adicionais: quais eram os conceitos de liberdade subjacente às suas interpretações e quais as suas expectativas quanto ao futuro da democracia? Para refletir sobre isso, tomemos uma passagem de Benjamin Constant, que em 1819 distinguia agudamente a evolução da natureza do conceito de liberdade no Ocidente:

O objetivo dos antigos era compartilhar o poder social entre todos os cidadãos de uma mesma pátria. A isso chamavam liberdade. O objetivo 
dos modernos é a segurança nos desfrutes privados. Chamamos liberdade às garantias acordadas pelas instituições para seguir gozando-os. ${ }^{38}$

Constant considerava que a liberdade dos antigos se efetivava na esfera pública, na arena política, por meio da manifestação de virtudes cívicas, do espírito de responsabilidade em relação ao Estado e ao bem comum da sociedade. Em contrapartida, a liberdade dos modernos se realizava na esfera privada, mediante a manifestação exclusiva dos interesses individuais e egoístas.

Entendemos que a perspectiva de Constant traduzia teoricamente a visão dos federalistas que haviam participado da elaboração da Constituição dos Estados Unidos. E era também a visão compartilhada por Alberdi, ao enfatizar o papel das instituições republicanas como garantia dos interesses privados. ${ }^{39} \mathrm{O}$ papel principal da ordem repúblicana argentina deveria ser garantir a plena manifestação das liberdades civis para o estímulo da atividade econômica e do progresso material. À republica dos cidadãos plenos caberia zelar pela ordem da república dos habitantes produtores. Em contrapartida, as perspectivas de Sarmiento e Tocqueville abraçavam o conceito antigo de liberdade, que se traduzia na defesa ardorosa do papel da atividade política e do caráter virtuoso do cidadão, de cuja combinação dependia a conjuração da tirania. ${ }^{40}$ Esse foi um tema caro para Tocqueville - sobretudo no segundo volume de A Democracia na América - que via no apego do homem moderno às pequenas paixões, ao enriquecimento e à vida materialmente cômoda, ou seja, no recolhimento à esfera priva$\mathrm{da}$, as condições para o desenvolvimento do despotismo, pois isso fazia-se acompanhar da despreocupação com os assuntos públicos. Enfim, movidos por forças opostas, de serem livres e ao mesmo tempo de serem conduzidos, a liberdade humana corria um sério risco caso os homens renunciassem à sua soberania ativa e preferissem escolher um tutor para exercer as responsabilidades políticas.

Como analisamos até aqui, apesar da identificação com o liberalismo, a admiração pelos Estados Unidos e o receio em relação aos setores populares, as perspectivas entre as três figuras aqui abordadas 
não eram unívocas, o que em parte pode ser creditado à sua posição social e política em seus respectivos países. Enquanto Tocqueville era integrante de uma classe social posicionada defensivamente em face das mudanças políticas e sociais da França e do mundo, Alberdi e Sarmiento pertenciam a uma elite dirigente em ascensão, cujos principais obstáculos tinham sido derrubados com a desarticulação do poder dos caudilhos.

Em tais circunstâncias, as expectativas quanto ao futuro obedeciam a critérios diferentes e contrapostos. Num extremo, Tocqueville, embora tivesse desenvolvido um diagnóstico positivo da situação democrática vivida nos Estados Unidos, mostrava-se muito receoso quanto às ameaças que a democracia norte-americana oferecia para a manutenção do direito à liberdade individual. Em contraste, Sarmiento e Alberdi, apesar da realidade adversa da Argentina em meados do século XIX e das muitas divergências que tiveram entre si, identificaram-se na crença otimista de um futuro próspero e democrático para o seu país.

A leitura e apropriação das idéias tocquevilleanas implicou também uma certa dose de traição. A despeito da admiração pelas idéias de Tocqueville, os dois argentinos subverteram o seu juízo pessimista a respeito do futuro político da América Latina, território em que a democracia seria impraticável. Pois Tocqueville tinha a convicção de que as constituições dos países latino-americanos, por melhores que fossem, não conseguiriam tornar a democracia uma realidade em vista do seu povo ser desprovido de costumes consoantes com as exigências desse regime político. ${ }^{41}$ Como para muitos outros artistas, escritores, reformadores e revolucionários do mundo político e social latino-americano, a crença na transformação também foi para Sarmiento e Alberdi mais forte que os obstáculos interpostos pela realidade.

As três visões aqui analisadas conceberam a democracia nos termos e limites do pensamento ilustrado oitocentista. Na Argentina mas também no restante da América Latina -, a construção da ordem liberal atendeu aos interesses de segmentos políticos, intelectuais e de classe em contraposição aos setores populares, à Igreja, aos caudilhos e às correntes conservadoras. Instituições e direitos foram afirmados co- 
mo expressão de uma concepção moderna e republicana do mundo, mas isso ocorreu à custa da marginalização e da exclusão da maior parte da sociedade. Aos constrangimentos legais à participação dos cidadãos, somaram-se o controle dos notáveis sobre as candidaturas, a coação dos poderosos sobre os eleitores e a manipulação dos resultados das eleições, formando um conjunto que dava um caráter oligárquico aos regimes políticos filiados ao projeto liberal. A superação da "ficção democrática" ali estabelecida dependeu das lutas políticas e sociais pela ampliação da cidadania, como parte de um processo de construção da democracia ainda em curso na América Latina, e, por que não, também nos Estados Unidos.

BEIRED, J. L. B. Tocqueville, Sarmiento and Alberdi: three visions on Democracy in Americas. História. São Paulo, v.22, n. 2, pp. 59-78, 2003.

\begin{abstract}
A BSTRACT: This article analyses comparatively three important ideologists of different continents of XIXth, that studied the concept of Democracy in the liberal context. It explains concepts and propositions of most representative works of those thinkers, articulated to their political and ideological visions in the specific contexts in which they lived.
\end{abstract}

KEY Wor DS: Alexis de Tocqueville; Domingo Faustino Sarmiento; Juan Bautista Alberdi.

\title{
NOTAS
}

${ }^{1}$ Versões preliminares deste trabalho foram apresentadas no seminário Temporalidade, Memória e História Política: Alexis de Tocqueville, realizado em maio de 2002, na FCL-UNESP, e no XXII Simpósio Nacional de História, em julho de 2003.

${ }^{2}$ Departamento de História - FCL - UNESP - CEP - 19806-900 - Assis - SP.

${ }^{3}$ BOTANA, N. La tradición republicana. Buenos Aires: Sudamericana, 1984, p. 492.

${ }^{4}$ GUERRA, F. X. Modernidad e independencias. Ensayos sobre las revoluciones hispánicas. Madrid: Mapfre, 1992, p. 370.

${ }^{5}$ Neste trabalho utilizamos a tradução brasileira mais recente, acompanhada das 
notas da edição da Biblioteca Ayacucho: SARMIENTO, D. F. Facundo: Civilização e Barbárie. Petrópolis: Vozes, 1997.

${ }^{6}$ ALBERDI, J. B. Bases y Puntos de Partida para la Reorganización de la Republica Argentina. Buenos Aires: Tor, 1957.

${ }^{7}$ Nossa abordagem insere-se na perspectiva de ROSANVALLON, P. Pour une histoire conceptuelle du politique. In: Revue de Synthèse, IV, n. 1/2, janvier- juin, 1986, pp. 93-105.

${ }^{8}$ No Chile, refugiou-se das perseguições dos caudilhos federais em guerra contra os unitários do interior argentino, permanecendo entre 1840 e 1851, quando incorporou-se juntamente com Bartolomé Mitre ao exército do General Urquiza para lutar contra os caudilhos que governavam a Confederação Argentina.

${ }^{9}$ Como próprio do romantismo argentino do século XIX, no Facundo dissolvemse as fronteiras entre o gênero literário e histórico, ao mesmo tempo que na sua narrativa emerge uma análise simultaneamente política, antropológica e sociológica da realidade Argentina. Ver MYERS, J. Hacia la completa palingenesia y civilización de las naciones americanas: literatura romántica y proyecto social, 18301870. In PIZARRO, A. (Org.). América Latina: Palavra, literatura e cultura. São Paulo: Memorial; Campinas: Unicamp, 1994, pp. 223-224.

${ }^{10}$ SARMIENTO, D. F. Op. cit., p. 48. Lembremos que na época de redação do Facundo, a expressão "América Latina" não era usual, sendo utilizada "América do Sul" como forma predominante.

${ }^{11}$ A obra foi publicada inicialmente como folhetim no jornal El Progreso, de Santiago do Chile e em seguida sob a forma de livro na mesma cidade pela Imprenta del Progreso. Para uma interpretação do Facundo, ver PRADO, M. L. C. Para ler o Facundo de Sarmiento. In: América Latina no século XIX: tramas, telas e textos. São Paulo: Edusp, 1999, pp. 151-178.

${ }^{12}$ Força parapolicial que ameaçava e assassinava os opositores.

${ }^{13}$ SARMIENTO, D. F. Op. cit., p. 306.

${ }^{14}$ SARMIENTO, D. F. Correspondencia entre Sarmiento y Lastarría. 1844-1888. Buenos Aires: 1954, p. 37. Apud: POMER, L. (Org.). D. F. Sarmiento: Política. São Paulo: Ática, 1983, p. 133. A carta é de 1852.

${ }^{15}$ LIMONGI, F. P. O Federalista. In: WEFFORT, F. (Org.). Os clássicos da política. São Paulo: Ática, 1989, v. II, pp. 252-255. Ver especialmente o artigo número 10, de MADISON, J. O tamanho e as diversidades da União como um obstáculo às facções. In: WEFFORT, F. (Org.). Op. cit., pp. 262-272.

${ }^{16}$ Utilizamos aqui a seguinte edição: TOCQUEVILLE, A. de. La Democracia em América. México: Fondo de Cultura Económica, 1957. 
${ }^{17} \mathrm{O}$ conceito de democracia presente em A democracia na América é multifacetado, pois Tocqueville não formulou uma única e conclusiva definição do que entendia por isso. Oscila entre a sua compreensão como governo dotado de certas leis e formas políticas (lois) e como estado social que tende à igualdade (moeurs). Ver: SCHLEIFER, J. T. Como nació "La democracia en América" de Tocqueville. México: Fondo de Cultura Económica, 1987, pp. 287- 298.

${ }^{18}$ TOCQUEVILLE, A. de. Op. cit., pp. 548-561; 712-717.

${ }^{19}$ Idem, p. 329.

${ }^{20}$ SARMIENTO, D. F. Op. cit, pp. 45-46.

${ }^{21}$ GALVÃO, C. Q. Dos Infortúnios da Igualdade ao Gozo da Liberdade. Uma Análise do Pensamento Politico de Alexis de Tocqueville. São Paulo: Discurso Editorial, 2001, p. 64 .

${ }^{22}$ SARMIENTO, D. F. Op. cit., pp. 70 e 145.

${ }^{23}$ Idem, p. 115.

${ }^{24}$ Idem, p. 63.

${ }_{25}$ Tratava-se de Achille Murat e Michel Chevalier. BOTANA, N. La tradición republicana. Buenos Aires: Sudamericana, 1984, p. 353.

${ }^{26}$ BOTANA, N. Op. cit., p. 299.

${ }^{27}$ ROMERO, J. L. El Pensamiento Político de la Emancipación. In: Situaciones e Ideologías en Latinoamérica. México: UNAM, 1981, pp. 49-81.

${ }^{28}$ ALBERDI, J. B. Algunas notas explicativas del autor. In: Op. cit., p. 236. Essa nota foi redigida em Paris em 1873, e acrescida às edições posteriores do livro.

${ }^{29}$ ALBERDI, J. B. Op. cit., p. 72.

${ }^{30}$ Idem, pp. 36-38.

${ }^{31}$ Natálio Botana desenvolveu tal distinção em dois trabalhos: La tradición republicana, Buenos Aires: Sudamericana, 1984, e em El Orden Conservador. La Politica Argentina entre 1880 y 1916. Buenos Aires: Sudamericana, 1985.

${ }^{32}$ TOCQUEVILLE, A. Op. cit, pp. 785-786.

${ }^{33} \mathrm{O}$ texto aprovado apenas diferiu ligeiramente do sugerido por Alberdi, segundo o qual cada província deveria indicar o mesmo número de deputados e senadores representantes no Congresso para compor o colégio eleitoral que escolheria o presidente. ALBERDI, J.B. Op. cit., pp. 179-184; 203-213.

${ }^{34}$ CONSTANT, B. Da Liberdade dos Antigos comparada à dos Modernos. Revista de Filosofia Politica. Porto Alegre, n. 2, 1985, pp. 9-25. 
${ }^{35}$ ROSANVALLON, P. Le citoyen capacitaire. In: Le moment Guizot. Paris: Gallimard, 1985, pp. 95-104.

${ }^{36}$ Sarmiento tinha um completo fascínio pelos Estados Unidos, onde esteve por duas ocasiões, em 1847 e entre 1865 e 1868. Da primeira vez fez um périplo que incluiu diversos países europeus, e da segunda, na condição de ministro plenipotenciário, só retornou para assumir a presidência da República em 1868.

${ }^{37}$ BOTANA, N. Op. cit., pp. 340 - 342.

${ }^{38}$ CONSTANT, B. Da Liberdade dos Antigos comparada à dos Modernos. In: Op. cit., p. 15.

${ }^{39}$ Inversamente, os interesses privados também eram importantes para reforçar a manutenção do sistema republicano.

${ }^{40}$ BOTANA, N. Op. cit., p. 485.

${ }^{41}$ TOCQUEVILLE, A. de. Op. cit., p. 328.

Artigo recebido em 04/2003. Aprovado em 07/2003. 